\title{
Three-dimensional printing for cardiovascular diseases: from anatomical modeling to dynamic functionality
}

\author{
Hao Wang, Hongning Song, Yuanting Yang, Quan Cao, Yugang Hu, Jinling Chen, Juan Guo, Yijia Wang, Dan Jia, \\ Sheng Cao and Qing Zhou*
}

*Correspondence: qingzhou@whu.edu.cn Department of Ultrasound Imaging, Renmin Hospital of Wuhan University, Wuhan 430060, China

\begin{abstract}
Three-dimensional (3D) printing is widely used in medicine. Most research remains focused on forming rigid anatomical models, but moving from static models to dynamic functionality could greatly aid preoperative surgical planning. This work reviews literature on dynamic 3D heart models made of flexible materials for use with a mock circulatory system. Such models allow simulation of surgical procedures under mock physiological conditions, and are; therefore, potentially very useful to clinical practice. For example, anatomical models of mitral regurgitation could provide a better display of lesion area, while dynamic 3D models could further simulate in vitro hemodynamics. Dynamic 3D models could also be used in setting standards for certain parameters for function evaluation, such as flow reserve fraction in coronary heart disease. As a bridge between medical image and clinical aid, 3D printing is now gradually changing the traditional pattern of diagnosis and treatment.
\end{abstract}

Keywords: 3D printing, Cardiovascular disease, Mock circulatory system

\section{Background}

Three-dimensional (3D) printing is being increasingly applied to the treatment of cardiovascular diseases, especially in the diagnosis and treatment of structural heart disease [1-3]. Conventional, mostly rigid, 3D heart models are chiefly useful in displaying the cardiac structure. However, the development of flexible printing materials allows the fabrication of functional cardiovascular models that are further capable of hemodynamic testing and preoperative simulation. Their ability to help decide clinical strategy maximizes the value of $3 \mathrm{D}$ printing in this field.

\section{The origins and medical applications of 3D printing}

Three-dimensional printing employs the principle of additive manufacturing to produce prototypes or final products by stereoscopically stacking discrete materials under computer control. Specific software slices a 3D digital model into several two-dimensional planes. Specific printing materials such as powder or resin are then accumulated

(c) The Author(s) 2020. This article is licensed under a Creative Commons Attribution 4.0 International License, which permits use, sharing, adaptation, distribution and reproduction in any medium or format, as long as you give appropriate credit to the original author(s) and the source, provide a link to the Creative Commons licence, and indicate if changes were made. The images or other third party material in this article are included in the article's Creative Commons licence, unless indicated otherwise in a credit line to the material. If material is not included in the article's Creative Commons licence and your intended use is not permitted by statutory regulation or exceeds the permitted use, you will need to obtain permission directly from the copyright holder. To view a copy of this licence, visit http://creativecommons.org/ licenses/by/4.0/. The Creative Commons Public Domain Dedication waiver (http://creativecommons.org/publicdomain/zero/1.0/) applies to the data made available in this article, unless otherwise stated in a credit line to the data. 
layer-by-layer using a laser beam or hot melting. The superimposed layers then form the final product. The core idea of 3D printing originated at the end of the nineteenth century with the development of photosculpture and geomorphic forming technology. In 1984, Charles Hull applied optical technology to rapid prototyping, and in 1986 set up the world's first company to produce 3D printing equipment, 3D Systems $[4,5]$. Four core 3D-printing technologies-stereolithography (SLA) [6], selective laser sintering (SLS) [7], fused deposition modeling (FDM) [8], and three-dimensional printing (3DP) [9]-were patented between 1986 and 1993. They defined the preliminary development of the industry, and the current 3D printers still mainly employ them.

Recent medial applications of 3D printing include in dentistry [10-14], orthopedics [15-17], craniomaxillofacial surgery [18, 19], and even drug delivery [20-28]. For example, a 3D-printed SLS drill guide can be used to accurately sculpt a facial tumor [19]. Printed models can be used during orthopedic surgery to fix articular fractures and precisely position plates [16]. In drug delivery, digitally controlled 3D printing can create a personalized drug delivery system through the layer-by-layer fabrication of active and excipient ingredients according to the needs of the patient. Spritam ${ }^{\circledR}$, containing the antiepileptic drug Levoacetam, is the first FDA-approved 3D-printed drug. When compared with traditional tablets, its pharmacological activity is similar, but the solubilization time is shorter.

Although the research on applying 3D printing to the treatment of cardiovascular diseases is relatively scant, the technique can potentially play important roles in preoperative practice, diagnosis, and treatment. Schievano et al. [29] studied 12 patients who planned to undergo pulmonary valve implantation, and found that surgeons considered a 3D-printed heart model to be more beneficial than image data when determining whether to perform valve replacement. Sodian et al. [30] made a 3D model based on magnetic resonance imaging (MRI) data as an aid to determine an operation plan for a patient with a left subclavian artery complicated with descending aorta malformation. The disinfected model was then used in the operating room for intraoperative localization. Overall, printed cardiovascular models show great potential advantages in assisting both preoperative decision making and intraoperative navigation. The history of 3D printing and its medical applications are summarized in Fig. 1.

\section{Overview of cardiovascular 3D printing} Imaging data acquisition

Accurate and reliable imaging data are the basis for accurate 3D model printing. At present, these data are most commonly from computed tomography $(\mathrm{CT})$ imaging, cardiac MRI, and echocardiography. Cardiovascular CT imaging has high spatial and density resolutions, and so it is the most often used technique for cardiac modeling in clinical studies. As the heart is composed of muscle and connective tissue, its internal density differences are difficult to show clearly under the conditions of a plain CT scan. Angiography CT scanning can enhance the display of cardiac structures. In contrast mode, the areas of high-density display in CT images are cardiac chambers and blood vessels, so $\mathrm{CT}$ images are the preferred data source for 3D printing of the cardiac cavity and vascular structure [31-33]. Models for maxillofacial surgery usually use data reconstructed from slice thicknesses of $0.5-1 \mathrm{~mm}$, whereas models of the pelvis and long bones can 


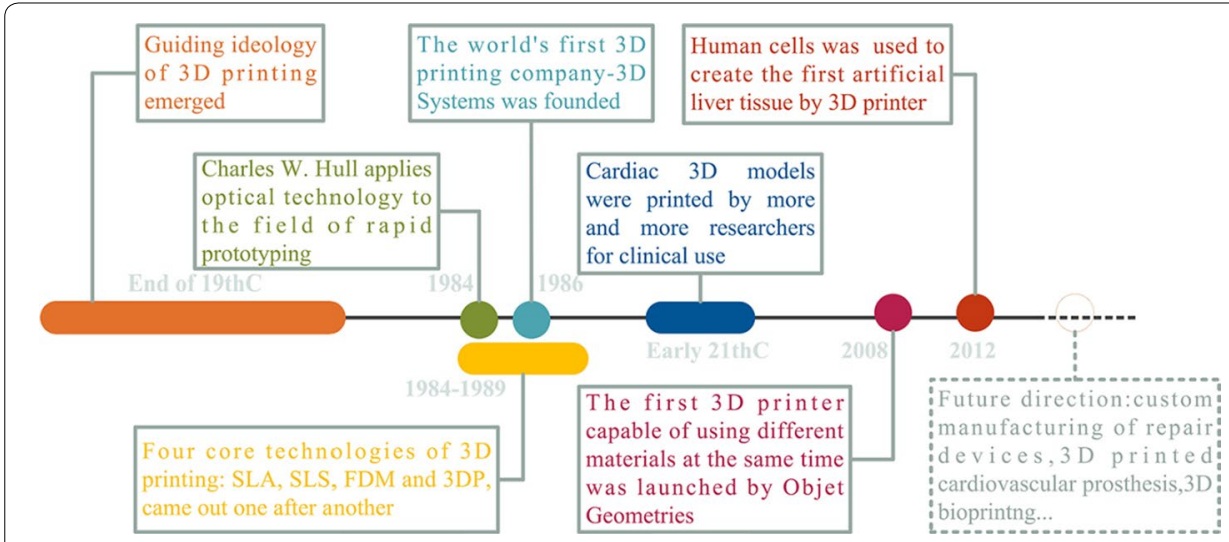

Fig. 1 History of 3D printing and its medical applications

use slice thicknesses up to $2 \mathrm{~mm}$. Cardiovascular modeling commonly employs 0.75 to $1 \mathrm{~mm}$ slice thicknesses with a smoother kernel. However, as CT scanning uses radioactive materials and is an invasive examination, not all cardiac structures are suitable for cardiac CT imaging. Cardiovascular magnetic resonance (CMR) has certain advantages over cardiac CT in displaying the heart's soft tissue or valves [34-37]. Significant improvements to the spatial and temporal resolutions of transthoracic and transesophageal 3D echocardiography make it another alternative technology for acquiring reliable source data for 3D printing [38-41].

As the heart is a relatively complex organ, a single data source may not be able to provide a complete picture of its anatomy. The recent work has fused images from multiple sources for 3D printing [36, 42-44] to significantly improve the depiction of complex anatomical details in the heart and provide more comprehensive information to aid intervention for structural heart disease and preoperative planning.

\section{Imaging data postprocessing}

Postprocessing isolates the target structures from a 3D volume dataset (in DICOM format) derived from medical imaging data. Commonly used software for medical image postprocessing includes 3D-Slicer, Horos, OsiriX, Mimics, and 3-Matic. These programs usually employ threshold segmentation to segment the required structure according to the different gray values of different tissues in the image. For example, the blood pool shows a lower signal intensity than the neighboring tissues, thereby delineating the intraluminal contour. The final digital model is exported in STL format and input into a 3D printer to obtain a 3D cardiovascular structure model.

\section{$3 \mathrm{D}$ printing procedures}

As described above, 3D printers are of four main types: SLA, SLS, FDM, and 3DP. SLA uses liquid photosensitive resin for rapid prototyping, which can quickly condense to a solid under laser irradiation. Its major advantage is the ability to create complex shapes with internal structures and extremely high feature resolution $(\sim 1.2 \mu \mathrm{m})$ [45]. However, there are few types of photosensitive resin, and the cost is relatively expensive. FDM is the most widely used 3D printing method. It involves first melting the material, and then spraying it through a computer-controlled extrusion nozzle. A 3D model is established 
Table 1 Comparison of four common 3D printing methods

\begin{tabular}{|c|c|c|c|c|}
\hline Printing method & SLA & SLS & 3DP & FDM \\
\hline Resolution & High & Medium & Medium & Low \\
\hline Surface quality & Smooth & Medium & Medium & Rough \\
\hline Cost & Relatively expensive & Medium & Medium & $\begin{array}{l}\text { Low-cost machines } \\
\text { and materials }\end{array}$ \\
\hline Materials & Photosensitive resin & $\begin{array}{l}\text { Wax, metal, ceramic } \\
\text { powder }\end{array}$ & $\begin{array}{l}\text { Wax, metal, ceramic } \\
\text { powder }\end{array}$ & $\begin{array}{l}\text { Polymers: PLA, ABS, } \\
\text { PVA }\end{array}$ \\
\hline Other features & $\begin{array}{l}\text { Limited to photopoly- } \\
\text { mers; supports } \\
\text { printing of flexible } \\
\text { materials }\end{array}$ & $\begin{array}{l}\text { Design freedom; no } \\
\text { need for support; } \\
\text { no post processing } \\
\text { needed }\end{array}$ & $\begin{array}{c}\text { Adhesive sprayed } \\
\text { through nozzle }\end{array}$ & $\begin{array}{l}\text { Limited to materials } \\
\text { that melt }\end{array}$ \\
\hline
\end{tabular}

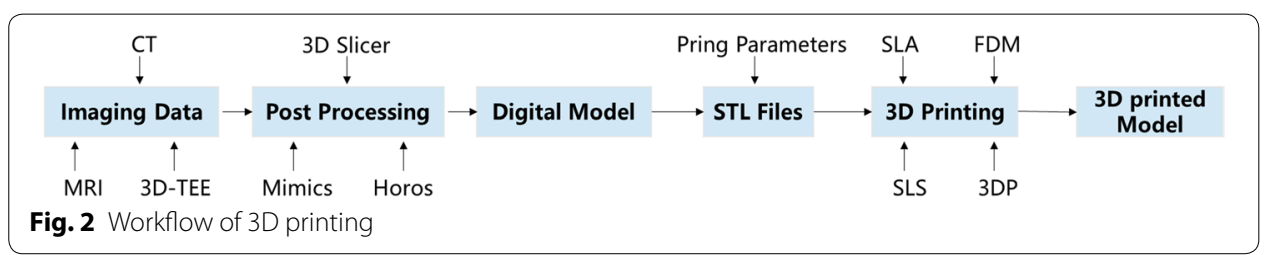

by the layer-by-layer accumulation of the material. Disadvantages include low printing accuracy and poor printing effect for soft materials. Detailed advantages and disadvantages of the four printing types are listed in Table 1.

The financial and time costs depend greatly on the size and complexity of the printed structure and the material used. An FDM print of the mitral annulus takes about $30 \mathrm{~min}$ [46], whereas a simplified heart model may take about 3 days [47]. The photosensitive resin for SLA printing is usually more expensive than the plastic polymer used in FDM printing. An SLA print of the left atrial appendage using TangoPlus (a photosensitive resin) costs about $\$ 250$ [48], whereas an FDM print of the full heart using ABS (a plastic polymer) only costs about $\$ 10$ [49].

\section{Accuracy and reliability of 3D printed models}

The mean deviation between a 3D printed heart model and medical images is about $0.4 \mathrm{~mm}$ [50], which can be considered negligible in clinical use. This is because the 3D printing process works within tolerances, and models typically contract as the polymer solidifies. Greil et al. [34] used multislice CT and CMR imaging to scan the hearts of five patients with congenital heart disease, and obtained high-resolution 3D models by SLA printing, whose accuracy (about $0.15 \mathrm{~mm}$ ) was higher than that of the imaging techniques, confirming that printing will not reduce the imaging accuracy. Figure 2 shows the workflow of $3 \mathrm{D}$ printing.

\section{Anatomical 3D models and cardiovascular disease}

\section{Conventional materials used for 3D anatomical models}

Conventional materials used for 3D printing (excepting bioactive materials used for 3D bio-printing) mainly include liquid photosensitive resin and polymers (either powders or fibers) [51]. In the past, 3D printing was mainly used to design personalized implants 
for orthopedic and joint surgery patients or to aid surgical navigation for such patients. Therefore, rigid materials, such as photosensitive resin and metal powder were mostly considered, as they meet the requirements of hardness and stress. More recent research has considered 3D printing polymers (such as PLA and ABS) for use in treating cardiovascular diseases. These materials are relatively inexpensive, and can depict specific structures of the heart, although with very different hardness and elasticity.

\section{Applications of anatomical 3D models in treating cardiovascular diseases}

The above materials simulate only the shape but not the physical properties of cardiac and other tissue structures. They are therefore mostly used in the diagnosis and treatment of structural heart disease (such as cardiovascular disease and valvular disease), aneurysm, and other large vascular diseases, as they can clearly display pathological or abnormal structures. Models of congenital heart disease such as atrial and ventricular defects can clarify their locations and relationships with neighboring structures such as the superior and inferior vena cava, aorta, mitral valve, and tricuspid valve, and so they help to evaluate whether the patient is suitable for interventional closure and the selection of an appropriate size of occluder. Wang et al. [52] used CT data to print a 3D heart model of a patient after atrial septal defect surgery, which clearly showed that the sealing device completely covered the edge of the defect, and so confirmed the role of 3D printing in postoperative evaluation. Table 2 summarizes the cardiovascular applications of 3D models.

\section{Limitations of anatomical 3D cardiovascular models}

Although anatomical models can assist clinicians, especially surgeons, in planning operations and selecting devices, it is not guaranteed that a decision made using a rigid 3D

Table 2 Applications of 3D anatomical models to treating cardiovascular diseases

\begin{tabular}{|c|c|c|c|}
\hline Condition & Material & Printing method & Purpose \\
\hline \multicolumn{4}{|l|}{ Congenital heart disease } \\
\hline $\begin{array}{l}\text { Atrial septal defect [33, } \\
53,54]\end{array}$ & $\begin{array}{l}\text { PLA, resin, polyurethane } \\
\text { filament }\end{array}$ & FDM SLA & $\begin{array}{l}\text { Preoperative evaluation; } \\
\text { transcatheter device closure } \\
\text { simulation }\end{array}$ \\
\hline $\begin{array}{l}\text { Ventricular septal defect } \\
\text { [55-58] }\end{array}$ & PLA, gypsum, cyanoacrylate & FDM & $\begin{array}{l}\text { Congenital heart disease edu- } \\
\text { cation for medical students; } \\
\text { transcatheter device closure } \\
\text { simulation }\end{array}$ \\
\hline $\begin{array}{l}\text { Complex congenital heart } \\
\text { disease: e.g., endocar- } \\
\text { dial cushion defect [54, } \\
\text { 59], double-outlet right } \\
\text { ventricle [56, 60-62] }\end{array}$ & PLA, resin, VeroMagenta & FDM SLA & $\begin{array}{l}\text { Improve understanding of } \\
\text { congenital heart disease; } \\
\text { surgical management }\end{array}$ \\
\hline \multicolumn{4}{|l|}{ Heart valve disease } \\
\hline Mitral valve disease [63-65] & PLA, ABS & FDM & Surgical management \\
\hline Tricuspid valve disease [66] & ABS & FDM & $\begin{array}{l}\text { Clinical decision-making; sur- } \\
\text { gical planning; education }\end{array}$ \\
\hline Aortic valve disease $[67,68]$ & Resin, PLA & FDM SLA & Surgical planning and training \\
\hline \multicolumn{4}{|l|}{ Others } \\
\hline Arterial aneurysm [69] & Resin & SLA & $\begin{array}{l}\text { Preoperative planning; post- } \\
\text { operative evaluation }\end{array}$ \\
\hline
\end{tabular}


model perfectly suits in vivo reality. Consider an atrial septum defect, for which the compression ratio of an implanted occluder and the shunt around it under normal cardiac pressure could clearly not be obtained using a rigid 3D model with very different properties form the actual heart. Researchers have therefore attempted to maximize the advantages offered by 3D printing by seeking realistically functioning cardiovascular models (with such as opening and closing valves and pulsating blood vessels). The recent emergence of flexible 3D printing materials (like TangoPlus) and the establishment of mock circulatory systems in vitro represent significant progress. Relevant research has combined 3D printing with mock circulatory systems to produce functional models of blood vessels, valves, and other structures to maximize the clinical usefulness of 3D printing.

\section{Functional models and cardiovascular disease}

To properly simulate tissue function requires both a flexible 3D cardiovascular model and its coupling with a mock circulatory system. Functional 3D models and their coupling with a mock circulatory system are shown in Fig. 3.

\section{Flexible materials for 3D cardiovascular models}

Any model for studying hemodynamics must accurately replicate the mechanical properties of the relevant tissues, and so must be more elastic and softer than conventional 3D printing materials. Recent advances include the 3D printing of rubber-like materials, which are gradually becoming widespread. A representative example is the TangoPlus series of materials, which can be printed as soft heart valves. The Connex3 Ojet series of 3D printers (Stratasys, Eden Prairie, MN, USA) can combine materials of different color and hardness, allowing reproduction of complex cardiac structures. Vukicevic et al. [70] used TangoPlus and Verowhite, respectively, to simulate the mitral valve and calcification on it, and tested the resulting model's mechanical parameters (such as bending and tensile moduli) in comparison with porcine leaflet tissue; the parameters were close to and consistent with those of the tissue. Maragiannis et al. [71] used the

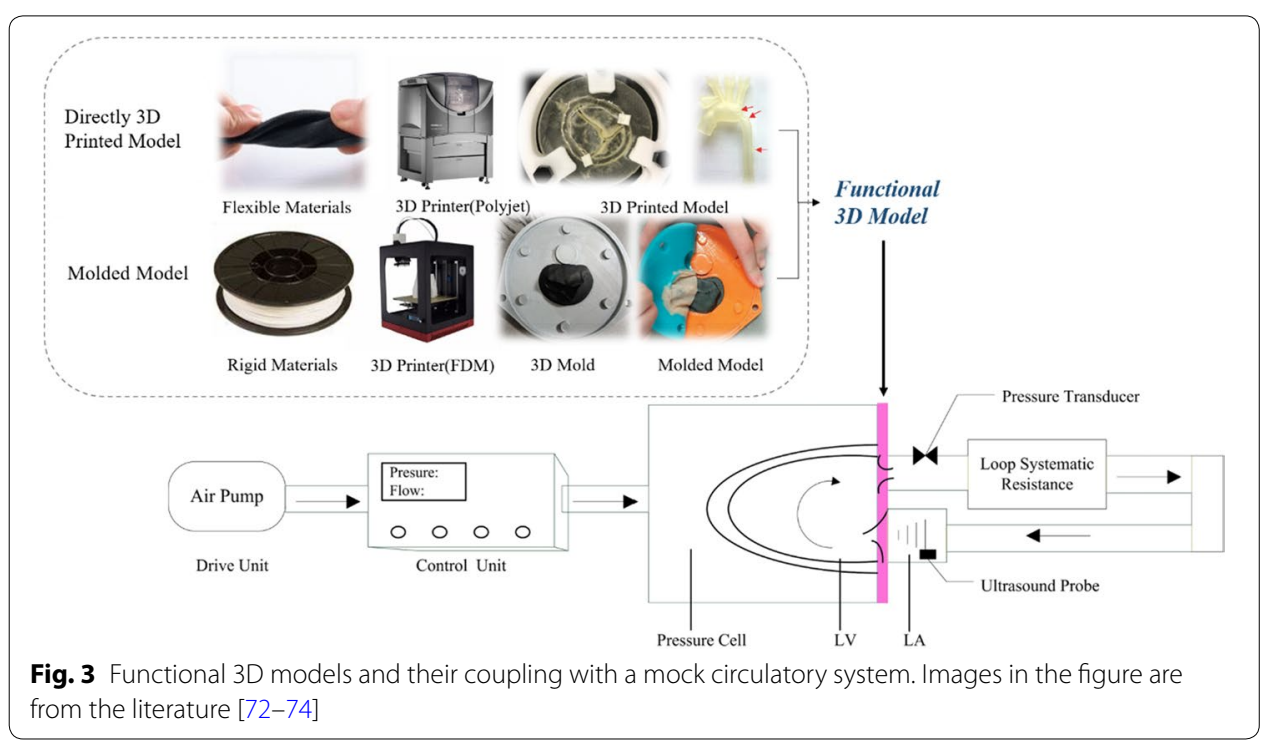


same two materials to create aortic valve complexes, and confirmed their feasibility for ultrasound imaging. Biglino et al. [72] made a blood vessel model using TangoPlus, and demonstrated its suitability for fabricating arteries, although its mechanical properties might not be suitable for modeling softer blood vessels.

Although directly printing rubber-like materials, such as TangoPlus can largely simulate the mechanical properties of cardiovascular tissues, it is relatively expensive. Using a rigid 3D model as a mold, a flexible model can alternatively be obtained by painting it with silicone (such as smooth-on, Echoflex). Scanlan et al. [73] compared 3D models of the tricuspid valve obtained by the two methods, and reported that both closely replicated the patient's anatomy, while the silicone model was better at simulating the texture of cutting and stitching. Based on the ultrasound images, a mitral valve prolapse model created by Olivia et al. [74] using Echoflex 00-30 also had good fidelity to the preoperative three-dimensional echocardiogram. Such materials are promising for the production of low-cost functional 3D cardiovascular models. The properties of common materials used in 3D printing are compared with those of human tissues in Table 3.

\section{In vitro mock circulatory systems}

A mock circulatory system is an experimental simulation of human hemodynamics that can be used to evaluate ventricular assistance devices, artificial valves, and other artificial cardiovascular components and to study the blood flow characteristics of cardiovascular diseases. Its basic components are described below.

\section{Drive unit}

A vacuum pump or air compressor is usually used as an actuator to power the device. The actuator is externally connected to a programmable logic controller to control the pulse of the heart or blood vessels. Pantalos et al. [77] placed a silicone ventricle in a chamber full of compressed gas to control its rhythmic contraction and relaxation.

\begin{tabular}{lllll}
$\begin{array}{l}\text { Table } 3 \text { Properties } \\
\text { of human tissues }\end{array}$ & common materials & used in 3 printing compared with those \\
\hline Material & Printing method & Elastic modulus (MPa) & Shore hardness & Cost \\
\hline Printing material $^{\text {a }}$ & & & & \\
PLA & FDM & $3000-4000$ & - & Low \\
ABS & FDM & 2200 & - & Low \\
Verowhite & SLA (Polyjet) & $2000-3000$ & $83-86$ Scale D & Medium \\
VeroClear & SLA (Polyjet) & $2000-3000$ & $83-86$ Scale D & Medium \\
Mold Star 15 & Casting on 3D printed model & 2.7 & 15 Scale A & Low \\
Echoflex 00-30 & Casting on 3D printed model & 1.4 & $00-30$ & Low \\
TangoPlus FLX930 & SLA (Polyjet) & - & $26-28$ Scale A & Expensive \\
Human Body & & & & - \\
Aorta/vena cava & - & $0.04-1.9[75]$ & - & - \\
Valves & - & $1.0-1.3[76]$ & - & - \\
Vasculature & - & $0.1-0.55[76]$ & - & - \\
Heart muscle & - & $0.08[76]$ & & - \\
\hline
\end{tabular}

a Data from manufacturers' websites

00-30: Grade 00 hardness, much lower than shore hardness 
Olivia et al. [74] used compressed gas to drive pneumatic pistons, which were connected to contractile loops around different levels of a ventricle model, to simulate the movement of different ventricular segments.

\section{Blood flow test system}

Doppler ultrasound: Doppler ultrasound can display the morphological characteristics of cardiovascular structures, evaluate the diameters of heart chambers and blood vessels, and monitor the blood flow velocity and pressure at different observation points in real time. Doppler flow imaging can also be used to evaluate the effects of surgery simulated in vitro, such as whether there is perivalvular leakage after valve replacement and whether there is residual shunt around the device.

4D-flow MRI: With the development of MRI technology and related software, 4D-flow MRI is gradually being applied in scientific research and clinical practice. It is a phase contrast technique that codes flow rates in the $x$-, $y$-, and $z$-directions [78]. It can quantitatively and visually evaluate characteristics of flow velocity (e.g., minimum and peak velocity, stroke volume, net flow, and reverse stroke) and wall shear stress (e.g., flow rate, pressure differential diagram, pulse wave velocity, and energy loss). The technique's disadvantages include long imaging times and the time-consuming postprocessing analysis.

Catheter-based monitoring: With a monitoring system such as Mac-Lab, a catheterbased monitoring device can plot pressure with respect to time. The plot's peak (rising or falling branch) can be used to evaluate fluid parameters such as vascular resistance and flow rate.

Particle image velocity measurement: Particle image velocity measurement is an optical method of measuring flow velocity by capturing (and analyzing) multiple snapshots to record the positions of particles in the flow field. It is commonly used for fluid imaging, and can easily obtain physical information, such as eddy currents and pressures, but it has high optical requirements for imaging particles in the fluid [79].

\section{Blood mimicking fluid}

Simulations of blood flow resistance generally use solutions, such as mixtures of water and glycerin that have a viscosity similar to that of blood (3.5-4.5 mPa /s). However, different test systems have different requirements for blood mimicking fluids. When using Doppler ultrasound, the addition of $5 \mu \mathrm{m}$ diameter nylon scattering particles to a fluid matrix containing water, glycerol, dextran, and surfactants improves the acoustic properties of the fluid and provides better imaging [80]. Velocity measurement using particle images requires the addition of tracer particles to the fluid.

\section{Application of functional cardiovascular models in diagnosis and treatment} Heart valve disease

Heart valve disease mainly includes valve stenosis and regurgitation, and usually involves changes in the structure and/or function of a valve owing to various causes. Recent advances in interventional operation, transcatheter valve replacement, valve repair, and valvuloplasty have increased treatment options. Accurate assessment of the location and extent of heart valve disease before surgery is therefore becoming increasingly important to treatment. Conventional heart valve models can display anatomical features, 
but cannot test their function. Printing a functional valve model with flexible materials and placing it in a mock circulatory system to test velocity, pressure gradient, and other parameters can help understand the severity of valvular disease. It can also simulate the operation to aid device selection, predict possible complications, and improve its success rate.

Severity assessment and surgical simulation of valvular disease: Maragiannis et al. [71] used TangoPlus and Verowhite to simulate the aortic valve leaflet and valvular calcification, respectively. They printed valve models of eight patients with severe aortic stenosis, and placed them in a mock circulatory system. Valve orifice area was measured by ultrasound Doppler and Gorlin formula to evaluate the severity of the disease. The blood flow velocity, pressure gradient, and valve orifice area measured on the model were consistent with in vivo measurements. This confirms the feasibility of using a 3D-printed functional aortic valve model combined with a simulated circulatory system to assess the severity of valve stenosis.

Vannelli et al. [81] created a left heart system model including left ventricle, aortic valve, and mitral valve by mold modeling. Driven by gas pressure, it simulated the contraction and relaxation of normal human ventricles and the opening and closing of the valve, with a left ventricular ejection fraction (51\%) within the normal range. Azad Mashari et al. [82] used similar devices to simulate the motion state of a pathological mitral valve during opening and closing, and obtained a blood flow spectrum consistent with that measured in vivo. Although the above studies to a certain extent simulated the motion of normal and pathological mitral valves and in vivo hemodynamic characteristics, due to the lack of systematic resistance in the device, the anterior velocity and pressure gradient generated by the ventricle during systole were not sufficient, and the results were not satisfactory. Olivia et al. [74] created 3D models of 10 patients with mitral valve regurgitation, and set up a pipe about $0.85 \mathrm{~m}$ high in a mock circulatory system to simulate the hydrostatic pressure generated by the aorta in vivo. The device could generate $107 \mathrm{mmHg}$ pressure during systole, more accurately reflecting the in vivo hemodynamic state. In addition, this study also simulated mitral valve repair, mitral clip, and other operations in 3D models, and determined the best surgical strategy by observing the changes in hemodynamics before and after surgery. It evaluated the effects of surgery, and predicted possible postoperative complications. Ultrasound images collected from the model were consistent with in vivo images, confirming the clinical value of 3D-printed heart valves in the diagnosis and treatment of diseases when coupled with mock circulatory devices.

Hemodynamic testing of artificial valves: In the past decade, transcatheter aortic valve replacement has become a life-saving alternative for patients who cannot tolerate conventional valve replacement [83]. The hemodynamic assessment of prosthetic valves relies on 3D-printed cardiovascular models to reproduce the anatomical structure and a mock circulatory system to simulate the in vivo blood flow state. Wentao Feng et al. [84] explored the possible deformation of artificial valve devices with different leaflet thicknesses for a patient with aortic root calcification by evaluating the effective valve area of the prosthetic valves, the average transvalvular pressure, and the valvular regurgitation. As the thickness of the valve increased, valve regurgitation due to device deformation became more severe. De Gaetano et al. [85] tested the pressure gradient, flow rate, 
effective valve orifice area, reverse flow, and other parameters of a new polymer heart valve under continuous and pulsating flow conditions using a mock circulatory device, and expected that this new kind of valve would soon find clinical applications. The above studies prove that $3 \mathrm{D}$ printing coupled with a mock circulatory system can help evaluate artificial valves and develop new devices for clinical use.

\section{Coronary heart disease}

Coronary artery disease, usually caused by coronary artery atherosclerosis, is one of the world's most fatal diseases. Percutaneous coronary intervention, especially intracoronary stent implantation, has proven to be an effective treatment. However, postoperative stent restenosis is a persistent problem. Improper stent implantation positions will enlarge the area of low WSS and subsequently stimulate epithelial cells in the vascular wall to grow outward; thereby, increasing the risk of postoperative restenosis [86]. HuJun Wang et al. [87] investigated the effects of different stent implantation positions on coronary artery hemodynamics and the area of the low-WSS region using 3D coronary artery models. The initial strategy was ostial stenting with the stent's top end staying in the upper area of the original stenosis. Three subsequent tests each raised the stent position $1.38 \mathrm{~mm}$ upward along the branch. The second position, called the half-cover strategy, had the fewest low-WSS areas, and was considered the best among the four compared. This shows that 3D printing coupled with a mock circulatory system can find the best position for implanting a coronary stent.

In addition to clinical strategy planning, 3D printing coupled with a mock circulatory system can also be used for setting standards for certain parameters for function evaluation. In addition to coronary angiography, intravascular ultrasound, and optical coherence tomography, the coronary flow reserve fraction (FFR), a function evaluation parameter for coronary artery stenosis and ischemic assessment, has received increasing attention. It is defined as the ratio of mean intravascular pressure in the distal end of coronary lesions to that in their proximal end in the state of maximal myocardial microcirculation congestion induced by adenosine and other drugs [88]. Kranthi et al. [89] used a 3D coronary model to test its variation in coronary stenosis vessels under different aortic pressures, finding that for a given stenotic vessel, the value gradually decreased as the aortic pressure increased. This also provides a reference for setting a standard of FFR for the evaluation of coronary stenosis in vivo.

\section{Vascular disease}

The treatment and diagnosis of aneurysms and macrovascular diseases can be aided using 3D-printed models coupling with a mock circulatory system. Anderson et al. [90] combined 3D printing with 4D phase contrast MRI in the visualization and quantification of blood flow characteristics in aneurysms. Hemodynamic simulation could also assess the rupture risk of aneurysm in vitro. In addition, the study also simulated the implant of a diverter in vitro, and observed changes of local hemodynamic characteristics before and after surgery, which helped predict the outcome of the procedure. Biglino et al. [72] used TangoPlus for 3D modeling and in vitro hemodynamic testing of patients with left ventricular hypoplasia syndrome with aortic coarctation. The anatomical structures of the ascending aorta, aortic arch, and descending aorta of the patient 
were reconstructed. The model did well in replicating capacity bearing $(70 / 40 \mathrm{mmHg})$, material compliance under pressure, and the consistency and anatomical structure. Knoops [91] used latex to make an adult lung circulation model. Wave intensity analysis identified three main waves (forward compression, backward compression, and forward expansion) in the main pulmonary artery. The model can be applied to the diagnosis of pulmonary hypertension, pulmonary unilateral stenosis, abnormal blood flow shunt after repair of transposition of the great arteries, and pulmonary artery disease such as Eisenmenger syndrome.

Table 4 summarizes applications of functional 3D models in treating cardiovascular diseases.

\section{Limitations}

A variety of factors, including excitation of autonomic nerves and endocrine regulation, affect hemodynamic characteristics. Although 3D printing can accurately reproduce the anatomical structures of the heart and the intracardiac pressure, it cannot simulate the in vivo physiological environment. Any parameters obtained using a simulation only reflect the intracardiac hemodynamic characteristics to a certain extent, which the model will not completely match. A further limitation is the enduring high cost (in terms of both time and money) of building an accurate dynamic 3D model. Furthermore, the potential clinical value of printed models, beyond "viewing" and preoperative simulation, needs to be further explored.

\section{Future Prospects}

Developments of 3D printing technology have attracted increasing numbers of researchers to apply it to biomedical engineering, especially in tissue engineering and regenerative medicine. When compared with traditional tissue engineering, which first prints a scaffold and then inoculates it with cells, 3D bioprinting could directly print different types of cells in the right spatial locations. By seeding cells into a 3D tissue-like structure, this technology could obtain higher cell density and realize a uniform cell density

Table 4 Applications of functional 3D models in treating cardiovascular diseases

\begin{tabular}{|c|c|c|}
\hline Application & Materials & Purpose \\
\hline \multicolumn{3}{|l|}{ Heart valve condition } \\
\hline Aortic valve stenosis [71] & TangoPlus, Verowhite & In vitro assessment of stenosis severity \\
\hline Mitral valve stenosis [82] & Mold star 15, Ecoflex 00-30 & In vitro assessment of stenosis severity \\
\hline Mitral valve regurgitation [74] & Mold star 15, Ecoflex 00-30 & $\begin{array}{l}\text { Surgical simulation: mitral valve repair, } \\
\text { mitral-clip }\end{array}$ \\
\hline Artificial valve $[84,85]$ & Silicone & $\begin{array}{l}\text { Device development: exploring relation- } \\
\text { ships between artificial valve thickness } \\
\text { and valve function }\end{array}$ \\
\hline \multicolumn{3}{|l|}{ Coronary heart disease } \\
\hline Coronary heart disease $[87,89]$ & Wax, VeroClear & $\begin{array}{l}\text { Surgical planning: optimal stent placement; } \\
\text { parameter evaluation criteria: FFR }\end{array}$ \\
\hline \multicolumn{3}{|l|}{ Vascular disease } \\
\hline Intracranial aneurysm [90] & Semi-translucent PLA & Surgical simulation: diverter implantation \\
\hline Abdominal aortic aneurysm [92] & Polyjet Material Rubber FLX930 & $\begin{array}{l}\text { Surgical simulation: transcatheter interven- } \\
\text { tion repair }\end{array}$ \\
\hline
\end{tabular}


distribution inside and outside the tissue. Direct 3D bioprinting of tissue or organs containing living cells has shown great potential, and has been widely studied, with examples including heart valves [93-95], skin [96, 97], nerves [98], liver tissue [99], alveoli [100], and even corneas [101] all being reported. More research is needed to meet the existing challenges of such as vascularization, organ rejection, and the lack of ideal bio ink.

Computational fluid dynamics (CFD) is another field receiving much research interest. CFD programs include ANSYS (ANSYS Inc., Pittsburgh, America) and COMSOL Multiphysics (COMSOL Inc., Stockholm, Sweden). Digital 3D modeling can be imported into CFD software after meshing. After setting boundary conditions, hemodynamic parameters at any point inside the model are easily obtained by CFD. CFD simulation has been used in drug delivery [102, 103] and the development of medical devices [104]. Pourmehran et al. [102] used CFD to simulate the air flow and magnetic particle deposition in a realistic human airway geometry obtained from CT images, thereby improving the efficiency of targeted drug delivery to the human lung in the presence of an external nonuniform magnetic field. CFD has also shown strong advantages in disease modeling and drug delivery.

Computer-aided design (CAD) was also an alternative method in planning interventions/treatment of cardiovascular diseases. For example, transcranial mitral valve replacement (TMVR) is an emerging method for the treatment of patients with severe mitral valve disease. However, the left ventricular outflow tract (LVOT) obstruction was a potentially fatal complication after surgery. Sung-Han Yoon et al. [105] successfully used CAD model based on the CT dataset to predict new LVOT area; thereby, prevent possible adverse clinical outcome. Besides, augmented reality technique has gained more attention and help plan surgery too [106].

\section{Conclusion}

There are wide ranging medical uses of 3D printing technology, but most research still focuses on anatomical models. The transition from static modeling to dynamic functionality requires more research and the development of materials closer in properties to human cardiovascular tissue. The combination of 3D-printed cardiovascular models and mock circulatory systems also depends on cross-disciplinary cooperation in biology, electrical engineering, and computer science. Further technological developments will ensure the increasingly important roles of 3D-printed functional heart models, maximizing the value of $3 \mathrm{D}$ printing in the treatment of cardiovascular diseases.

Abbreviations

MCS: Mock Circulatory System; SLA: Stereo Lithography Appearance; SLS: Selective Laser Sintering; FDM: Fused Deposition Modeling; 3DP: Three-Dimensional Printing; PLA: Polylactic Acid; ABS: Acrylonitrile Butadiene Styren.

Acknowledgements

The authors thank all the authors cited in this article for their outstanding work in applying 3D printing to the diagnosis and treatment of cardiovascular disease.

Author contributions

HW, HS, YY, JG, YW, DJ: literature collection and summary; QC, YH, LC: figures and tables; SC, QZ: article review and revision. All authors read and approved the final manuscript.

Funding

This study was funded by the National Nature Science Foundation of China (No. 81771849). 
Availability of data and materials

The authors will make all data detailed in this paper freely available.

Ethics approval and consent to participate

This article does not contain any studies with human participants or animals performed by any of the authors.

\section{Consent for publication}

Consent for publication was obtained for every individual person's data included in the study.

\section{Competing interests}

The authors have no competing interests to report.

Received: 12 August 2020 Accepted: 28 September 2020

Published online: 07 October 2020

\section{References}

1. Biglino G, Capelli C, Wray J, et al. 3D-manufactured patient-specific models of congenital heart defects for communication in clinical practice: feasibility and acceptability. BMJ Open. 2015;5(4):e007165. https://doi.org/10.1136/ bmjopen-2014-007165.

2. Kim MS, Hansgen AR, Wink $O$, et al. Rapid prototyping: a new tool in understanding and treating structural heart disease. Circulation. 2008;117(18):2388-94. https://doi.org/10.1161/CIRCULATIONAHA.107.740977.

3. Schmauss D, Haeberle S, Hagl C, et al. Three-dimensional printing in cardiac surgery and interventional cardiology: a single-centre experience. Eur J Cardiothorac Surg. 2015;47(6):1044-52. https://doi.org/10.1093/ejcts/ezu310.

4. Mitsouras D, Liacouras $P$, Imanzadeh A, et al. Medical 3D Printing for the Radiologist. Radiographics. 2015;35(7):1965-88. https://doi.org/10.1148/rg.2015140320.

5. Vukicevic M, Mosadegh B, Min JK, et al. Cardiac 3D Printing and its Future Directions. JACC Cardiovasc Imaging. 2017;10(2):171-84. https://doi.org/10.1016/j.jcmg.2016.12.001.

6. Hull CW. Apparatus for production of three-dimensional objects by stereolithography: U.S. Patent 5,556,590. 1996-9-17.

7. Grube KW, Beaman J J. Radiant heating apparatus for providing uniform surface temperature useful in selective laser sintering: U.S. Patent 5,155,321. 1992-10-13.

8. Crump S S. Apparatus and method for creating three-dimensional objects: U.S. Patent 5,121,329. 1992-6-9.

9. Sachs E M, Haggerty J S, Cima M J, et al. Three-dimensional printing techniques: U.S. Patent 5,204,055. 1993-4-20.

10. Chan HL, Misch K, Wang HL. Dental imaging in implant treatment planning. Implant Dent. 2010;19(4):288-98. https://doi.org/10.1097/ID.0b013e3181e59ebd.

11. Fortes $\mathrm{JH}$, de Oliveira-Santos C, Matsumoto W, et al. Influence of 2D vs 3D imaging and professional experience on dental implant treatment planning. Clin Oral Investig. 2019;23(2):929-36. https://doi.org/10.1007/s0078 4-018-2511-1.

12. Hatcher DC, Dial C, Mayorga C. Cone beam CT for pre-surgical assessment of implant sites. J Calif Dent Assoc. 2003;31(11):825-33.

13. Klein HM, Schneider W, Alzen G, et al. Pediatric craniofacial surgery: comparison of milling and stereolithography for 3D model manufacturing. Pediatr Radiol. 1992;22(6):458-60. https://doi.org/10.1007/BF02013512.

14. Scarfe WC, Farman AG, Sukovic P. Clinical applications of cone-beam computed tomography in dental practice. J Can Dent Assoc. 2006:72(1):75-80

15. Haq J, Patel N, Weimer K, et al. Single stage treatment of ankylosis of the temporomandibular joint using patientspecific total joint replacement and virtual surgical planning. Br J Oral Maxillofac Surg. 2014;52(4):350-5. https:// doi.org/10.1016/j.bjoms.2014.01.004.

16. Lethaus B, Bloebaum M, Essers B, et al. Patient-specific implants compared with stored bone grafts for patients with interval cranioplasty. J Craniofac Surg. 2014;25(1):206-9. https://doi.org/10.1097/SCS.0000000000000396.

17. Tack P, Victor J, Gemmel P, et al. 3D-printing techniques in a medical setting: a systematic literature review. Biomed Eng Online. 2016;15(1):115. https://doi.org/10.1186/s12938-016-0236-4.

18. Chen J, Zhang Z, Chen $X$, et al. Design and manufacture of customized dental implants by using reverse engineering and selective laser melting technology. J Prosthet Dent. 2014;112(5):1088-95. https://doi.org/10.1016/j.prosd ent.2014.04.026

19. Saijo H, Igawa K, Kanno Y, et al. Maxillofacial reconstruction using custom-made artificial bones fabricated by inkjet printing technology. J Artif Organs. 2009;12(3):200-5. https://doi.org/10.1007/s10047-009-0462-7.

20. Beck RCR, Chaves PS, Goyanes A, et al. 3D printed tablets loaded with polymeric nanocapsules: an innovative approach to produce customized drug delivery systems. Int J Pharm. 2017;528(1-2):268-79. https://doi. org/10.1016/j.ijpharm.2017.05.074

21. Fu J, Yin H, Yu X, et al. Combination of 3D printing technologies and compressed tablets for preparation of riboflavin floating tablet-in-device (TiD) systems. Int J Pharm. 2018;549(1-2):370-9. https://doi.org/10.1016/j.ijpha rm.2018.08.011.

22. Goyanes A, Buanz AB, Hatton GB, et al. 3D printing of modified-release aminosalicylate (4-ASA and 5-ASA) tablets. Eur J Pharm Biopharm. 2015;89:157-62. https://doi.org/10.1016/j.ejpb.2014.12.003.

23. Hinton TJ, Hudson A, Pusch K, et al. 3D printing PDMS elastomer in a hydrophilic support bath via freeform reversible embedding. ACS Biomater Sci Eng. 2016:2(10):1781-6. https://doi.org/10.1021/acsbiomaterials.6b00170.

24. Tan DK, Maniruzzaman M, Nokhodchi A. Advanced pharmaceutical applications of hot-melt extrusion coupled with fused deposition modelling (FDM) 3D printing for personalised drug delivery. Pharmaceutics. 2018. https:// doi.org/10.3390/pharmaceutics 10040203. 
25. Yang $\mathrm{Y}$, Wang $\mathrm{H}$, Li $\mathrm{H}$, et al. 3D printed tablets with internal scaffold structure using ethyl cellulose to achieve sustained ibuprofen release. Eur J Pharm Sci. 2018;115:11-8. https://doi.org/10.1016/j.ejps.2018.01.005.

26. Ahookhosh K, Pourmehran O, Aminfar H, et al. Development of human respiratory airway models: A review. Eur J Pharm Sci. 2020;145:105233. https://doi.org/10.1016/j.ejps.2020.105233.

27. Pourmehran O, Cazzolato B, Tian Z, et al. Acoustically-driven drug delivery to maxillary sinuses: Aero-acoustic analysis. Eur J Pharm Sci. 2020;151:105398. https://doi.org/10.1016/j.ejps.2020.105398.

28. Pourmehran O, Arjomandi M, Cazzolato B, et al. The impact of geometrical parameters on acoustically driven drug delivery to maxillary sinuses. Biomech Model Mechanobiol. 2020;19(2):557-75. https://doi.org/10.1007/s1023 7-019-01230-5.

29. Schievano $S$, Migliavacca F, Coats $L$, et al. Percutaneous pulmonary valve implantation based on rapid prototyping of right ventricular outflow tract and pulmonary trunk from MR data. Radiology. 2007;242(2):490-7. https://doi. org/10.1148/radiol.2422051994.

30. Sodian R, Weber S, Markert M, et al. Stereolithographic models for surgical planning in congenital heart surgery. Ann Thorac Surg. 2007;83(5):1854-7. https://doi.org/10.1016/j.athoracsur.2006.12.004.

31. Faletti R, Gatti M, Cosentino A, et al. 3D printing of the aortic annulus based on cardiovascular computed tomography: Preliminary experience in pre-procedural planning for aortic valve sizing. J Cardiovasc Comput Tomogr. 2018;12(5):391-7. https://doi.org/10.1016/j.jcct.2018.05.016.

32. Hosny A, Dilley JD, Kelil T, et al. Pre-procedural fit-testing of TAVR valves using parametric modeling and 3D printing. J Cardiovasc Comput Tomogr. 2019;13(1):21-30. https://doi.org/10.1016/j.jcct.2018.09.007.

33. Valverde I, Gomez-Ciriza G, Hussain T, et al. Three-dimensional printed models for surgical planning of complex congenital heart defects: an international multicentre study. Eur J Cardiothorac Surg. 2017;52(6):1139-48. https:// doi.org/10.1093/ejcts/ezx208.

34. Greil GF, Wolf I, Kuettner A, et al. Stereolithographic reproduction of complex cardiac morphology based on high spatial resolution imaging. Clin Res Cardiol. 2007;96(3):176-85. https://doi.org/10.1007/s00392-007-0482-3.

35. Olejnik $P$, Juskanic $D$, Patrovic $L$, et al. First printed $3 D$ heart model based on cardiac magnetic resonance imaging data in Slovakia. Bratisl Lek Listy. 2018;119(12):781-4. https://doi.org/10.4149/BLL_2018_142.

36. Rajiah P, Tandon A, Greil GF, et al. Update on the role of cardiac magnetic resonance imaging in congenital heart disease. Curr Treat Options Cardiovasc Med. 2017;19(1):2. https://doi.org/10.1007/s11936-017-0504-z.

37. Whitaker J, Neji R, Byrne N, et al. Improved co-registration of ex-vivo and in-vivo cardiovascular magnetic resonance images using heart-specific flexible 3D printed acrylic scaffold combined with non-rigid registration. J Cardiovasc Magn Reson. 2019;21(1):62. https://doi.org/10.1186/s12968-019-0574-z.

38. Athanassopoulos GD. 3D printing for left atrial appendage (LAA) modeling based on transesophageal echocardiography: a step forward in closure with LAA devices. Cardiology. 2016;135(4):249-54. https://doi. org/10.1159/000448024.

39. Faroogi KM, Sengupta PP. Echocardiography and three-dimensional printing: sound ideas to touch a heart. J Am Soc Echocardiogr. 2015;28(4):398-403. https://doi.org/10.1016/j.echo.2015.02.005.

40. Muraru D, Veronesi F, Maddalozzo A, et al. 3D printing of normal and pathologic tricuspid valves from transthoracic 3D echocardiography data sets. Eur Heart J Cardiovasc Imaging. 2017;18(7):802-8. https://doi.org/10.1093/ ehjci/jew215.

41. Olivieri LJ, Krieger A, Loke YH, et al. Three-dimensional printing of intracardiac defects from three-dimensional echocardiographic images: feasibility and relative accuracy. J Am Soc Echocardiogr. 2015;28(4):392-7. https://doi. org/10.1016/j.echo.2014.12.016.

42. Hell MM, Achenbach S, Yoo IS, et al. 3D printing for sizing left atrial appendage closure device: head-to-head comparison with computed tomography and transoesophageal echocardiography. Eurolntervention. 2017. https ://doi.org/10.4244/EIJ-D-17-00359.

43. Kurup HK, Samuel BP, Vettukattil JJ. Hybrid 3D printing: a game-changer in personalized cardiac medicine? Expert Rev Cardiovasc Ther. 2015;13(12):1281-4. https://doi.org/10.1586/14779072.2015.1100076.

44. O'Neill B, Wang DD, Pantelic M, et al. Transcatheter caval valve implantation using multimodality imaging: roles of TEE, CT, and 3D printing. JACC Cardiovasc Imaging. 2015;8(2):221-5. https://doi.org/10.1016/j.jcmg.2014.12.006.

45. Melchels FP, Feijen J, Grijpma DW. A review on stereolithography and its applications in biomedical engineering Biomaterials. 2010;31(24):6121-30. https://doi.org/10.1016/j.biomaterials.2010.04.050.

46. Mahmood F, Owais K, Montealegre-Gallegos M, et al. Echocardiography derived three-dimensional printing of normal and abnormal mitral annuli. Ann Card Anaesth. 2014;17(4):279-83. https://doi.org/10.4103/09719784.142062.

47. Abdel-Sayed $\mathrm{P}$, Kalejs M, von Segesser LK. A new training set-up for trans-apical aortic valve replacement. Interact Cardiovasc Thorac Surg. 2009;8(6):599-601. https://doi.org/10.1510/icvts.2009.204149.

48. Hachulla AL, Noble S, Guglielmi G, et al. 3D-printed heart model to guide LAA closure: useful in clinical practice? Eur Radiol. 2019;29(1):251-8. https://doi.org/10.1007/s00330-018-5569-x.

49. Farooqi KM, Saeed O, Zaidi A, et al. 3D printing to guide ventricular assist device placement in adults with congenital heart disease and heart failure. JACC Heart Fail. 2016;4(4):301-11. https://doi.org/10.1016/j.jchf.2016.01.012.

50. Lau IWW, Sun Z. Dimensional accuracy and clinical value of $3 \mathrm{~d}$ printed models in congenital heart disease: a systematic review and meta-analysis. J Clin Med. 2019. https://doi.org/10.3390/jcm8091483.

51. Garcia J, Yang Z, Mongrain R, et al. 3D printing materials and their use in medical education: a review of current technology and trends for the future. BMJ Simul Technol Enhanc Learn. 2018;4(1):27-40. https://doi.org/10.1136/ bmjstel-2017-000234.

52. Wang Z, Luo H, Gao C, et al. Three-dimensional printing model for the postoperative follow-up of atrial septal defect. Int J Cardiol. 2016;222:891-2. https://doi.org/10.1016/j.jicard.2016.08.046.

53. He L, Cheng GS, Du YJ, et al. Feasibility of device closure for multiple atrial septal defects with an inferior sinus venosus defect: procedural planning using three-dimensional printed models. Heart Lung Circ. 2019. https://doi. org/10.1016/j.hlc.2019.07.004. 
54. Zhu Y, Liu J, Wang L, et al. Preliminary study of the application of transthoracic echocardiography-guided threedimensional printing for the assessment of structural heart disease. Echocardiography. 2017;34(12):1903-8. https ://doi.org/10.1111/echo.13715

55. Lazkani M, Bashir F, Brady K, et al. Postinfarct VSD management using 3D computer printing assisted percutaneous closure. Indian Heart J. 2015;67(6):581-5. https://doi.org/10.1016/j.ihj.2015.09.021.

56. Shearn AIU, Yeong M, Richard $M$, et al. Use of $3 D$ models in the surgical decision-making process in a case of double-outlet right ventricle with multiple ventricular septal defects. Front Pediatr. 2019;7:330. https://doi. org/10.3389/fped.2019.00330.

57. Su W, Xiao Y, He S, et al. Three-dimensional printing models in congenital heart disease education for medical students: a controlled comparative study. BMC Med Educ. 2018;18(1):178. https://doi.org/10.1186/s1290 9-018-1293-0.

58. White SC, Sedler J, Jones TW, et al. Utility of three-dimensional models in resident education on simple and complex intracardiac congenital heart defects. Congenit Heart Dis. 2018;13(6):1045-9. https://doi.org/10.1111/ chd. 12673.

59. Mendez A, Gomez-Ciriza G, Raboisson MJ, et al. Apical muscular ventricular septal defects: surgical strategy using three-dimensional printed model. Semin Thorac Cardiovasc Surg. 2018;30(4):450-3. https://doi.org/10.1053/j. semtcvs.2018.07.002.

60. Bhatla P, Tretter JT, Ludomirsky A, et al. Utility and scope of rapid prototyping in patients with complex muscular ventricular septal defects or double-outlet right ventricle: does it alter management decisions? Pediatr Cardiol. 2017:38(1):103-14. https://doi.org/10.1007/s00246-016-1489-1.

61. Yoo SJ, van Arsdell GS. 3D printing in surgical management of double outlet right ventricle. Front Pediatr. 2017:5:289. https://doi.org/10.3389/fped.2017.00289.

62. Zhao L, Zhou S, Fan T, et al. Three-dimensional printing enhances preparation for repair of double outlet right ventricular surgery. J Card Surg. 2018;33(1):24-7. https://doi.org/10.1111/jocs.13523.

63. Kapur K, Garg N. Echocardiography derived three-dimensional printing of normal and abnormal mitral annuli. Ann Card Anaesth. 2014;17(4):283-4.

64. Owais K, Pal A, Matyal R, et al. Three-dimensional printing of the mitral annulus using echocardiographic data: science fiction or in the operating room next door? J Cardiothorac Vasc Anesth. 2014;28(5):1393-6.

65. Witschey WRT, Pouch AM, McGarvey JR, et al. Three-dimensional ultrasound-derived physical? Mitral valve modeling. Ann Thorac Surg. 2014;98(2):691-4.

66. Muraru D, Veronesi F, Maddalozzo A, et al. 3D printing of normal and pathologic tricuspid valves from transthoracic 3D echocardiography data sets. European Heart Journal Cardiovascular Imaging. 2016;18(7):jew215.

67. Gomes EN, Dias RR, Rocha BA, et al. Use of 3D printing in preoperative planning and training for aortic endovascular repair and aortic valve disease. Braz J Cardiovasc Surg. 2018;33(5):490-5. https://doi.org/10.21470 /1678-9741-2018-0101.

68. Sodian R, Schmauss D, Markert M, et al. Three-dimensional printing creates models for surgical planning of aortic valve replacement after previous coronary bypass grafting. Ann Thorac Surg. 2008;85(6):2105-8. https://doi. org/10.1016/j.athoracsur.2007.12.033.

69. Schmauss $D$, Juchem $G$, Weber $S$, et al. Three-dimensional printing for perioperative planning of complex aortic arch surgery. Ann Thorac Surg. 2014;97(6):2160-3. https://doi.org/10.1016/j.athoracsur.2014.02.011.

70. Vukicevic M, Puperi DS, Jane Grande-Allen K, et al. 3D Printed modeling of the mitral valve for catheter-based structural interventions. Ann Biomed Eng. 2017;45(2):508-19. https://doi.org/10.1007/s10439-016-1676-5.

71. Maragiannis D, Jackson MS, Igo SR, et al. replicating patient-specific severe aortic valve stenosis with functional $3 D$ modeling. Circ Cardiovasc Imaging. 2015;8(10):e003626. https://doi.org/10.1161/CIRCIMAGING.115.003626.

72. Biglino G, Verschueren P, Zegels R, et al. Rapid prototyping compliant arterial phantoms for in-vitro studies and device testing. J Cardiovasc Magn Reson. 2013;15:2. https://doi.org/10.1186/1532-429X-15-2.

73. Scanlan $A B$, Nguyen $A V$, llina $A$, et al. Comparison of $3 D$ echocardiogram-derived $3 d$ printed valve models to molded models for simulated repair of pediatric atrioventricular valves. Pediatr Cardiol. 2018;39(3):538-47. https:// doi.org/10.1007/s00246-017-1785-4.

74. Ginty OK, Moore JM, Xu Y, et al. Dynamic patient-specific three-dimensional simulation of mitral repair: can we practice mitral repair preoperatively? Innovations (Phila). 2018;13(1):11-22. https://doi.org/10.1097/IMI.00000 00000000463

75. Albanna MZ, Bou-AkI TH, Walters HL 3rd, et al. Improving the mechanical properties of chitosan-based heart valve scaffolds using chitosan fibers. J Mech Behav Biomed Mater. 2012;5(1):171-80. https://doi.org/10.1016/j.jmbbm .2011.08.021.

76. Mondschein RJ, Kanitkar A, Williams CB, et al. Polymer structure-property requirements for stereolithographic 3D printing of soft tissue engineering scaffolds. Biomaterials. 2017;140:170-88. https://doi.org/10.1016/j.biomateria Is.2017.06.005.

77. Pantalos GM, Koenig SC, Gillars KJ, et al. Characterization of an adult mock circulation for testing cardiac support devices. ASAIO J. 2004;50(1):37-46. https://doi.org/10.1097/01.mat.0000104818.70726.e6.

78. Liu J, Dyverfeldt P, Acevedo-Bolton G, et al. Highly accelerated aortic 4D flow MR imaging with variable-density random undersampling. Magn Reson Imaging. 2014;32(8):1012-20. https://doi.org/10.1016/j.mri.2014.05.004.

79. de Zelicourt D, Pekkan K, Kitajima H, et al. Single-step stereolithography of complex anatomical models for optical flow measurements. J Biomech Eng. 2005;127(1):204-7. https://doi.org/10.1115/1.1835367.

80. Ginty O, Moore J, Xia W, et al., Patient-specific indirectly 3D printed mitral valves for pre-operative surgical modelling, in: Spie Medical Imaging, 2017.

81. Vannelli C, Moore J, Mcleod J, et al., Dynamic heart phantom with functional mitral and aortic valves, in: Spie Medical Imaging, 2015.

82. Mashari A, Knio Z, Jeganathan J, et al. Hemodynamic testing of patient-specific mitral valves using a pulse duplicator: a clinical application of three-dimensional printing. J Cardiothorac Vasc Anesth. 2016;30(5):1278-85. https:// doi.org/10.1053/j.jvca.2016.01.013. 
83. Cao C, Ang SC, Indraratna P, et al. Systematic review and meta-analysis of transcatheter aortic valve implantation versus surgical aortic valve replacement for severe aortic stenosis. Ann Cardiothorac Surg. 2013;2(1):10-23. https:// doi.org/10.3978/j.issn.2225-319X.2012.11.09.

84. Feng $W$, Yang $X$, Liu Y, et al. An in vitro feasibility study of the influence of configurations and leaflet thickness on the hydrodynamics of deformed transcatheter aortic valve. Artif Organs. 2017;41 (8):735-43. https://doi. org/10.1111/aor.12833.

85. De Gaetano F, Serrani M, Bagnoli P, et al. Fluid dynamic characterization of a polymeric heart valve prototype (PoliValve) tested under continuous and pulsatile flow conditions. Int J Artif Organs. 2015;38(11):600-6. https://doi. org/10.5301/ijao.5000452.

86. Qu MJ, Liu B, Wang HQ, et al. Frequency-dependent phenotype modulation of vascular smooth muscle cells under cyclic mechanical strain. JVasc Res. 2007:44(5):345-53. https://doi.org/10.1159/000102278.

87. Wang $\mathrm{H}$, Liu J, Zheng $\mathrm{X}$, et al. Three-dimensional virtual surgery models for percutaneous coronary intervention (PCI) optimization strategies. Sci Rep. 2015;5:10945. https://doi.org/10.1038/srep10945.

88. Tonino PA, De Bruyne B, Pijls NH, et al. Fractional flow reserve versus angiography for guiding percutaneous coronary intervention. N Engl J Med. 2009;360(3):213-24. https://doi.org/10.1056/NEJMoa0807611.

89. Kolli KK, Min JK, Ha S, et al. Effect of varying hemodynamic and vascular conditions on fractional flow reserve: an in vitro study. J Am Heart Assoc. 2016. https://doi.org/10.1161/JAHA.116.003634.

90. Anderson JR, Klucznik R, Diaz O, et al. Quantification of velocity reduction after flow diverter placement in intracranial aneurysm: an ex vivo study with 3D printed replicas. Conf Proc IEEE Eng Med Biol Soc. 2015;2015:7300-3. https://doi.org/10.1109/EMBC.2015.7320077.

91. Knoops PGM, Biglino G, Hughes AD, et al. A mock circulatory system incorporating a compliant 3d-printed anatomical model to investigate pulmonary hemodynamics. Artif Organs. 2017;41(7):637-46. https://doi.org/10.1111/ aor.12809.

92. Meess KM, Izzo RL, Dryjski ML, et al. 3D printed abdominal aortic aneurysm phantom for image guided surgical planning with a patient specific fenestrated endovascular graft system. Proc SPIE Int Soc Opt Eng. 2017. https:// doi.org/10.1117/12.2253902.

93. Duan B, Hockaday LA, Kang KH, et al. 3D bioprinting of heterogeneous aortic valve conduits with alginate/gelatin hydrogels. J Biomed Mater Res A. 2013;101(5):1255-64. https://doi.org/10.1002/jbm.a.34420.

94. Hockaday LA, Kang KH, Colangelo NW, et al. Rapid 3D printing of anatomically accurate and mechanically heterogeneous aortic valve hydrogel scaffolds. Biofabrication. 2012;4(3):035005. https://doi.org/10.1088/17585082/4/3/035005

95. Lueders C, Jastram B, Hetzer R, et al. Rapid manufacturing techniques for the tissue engineering of human heart valves. Eur J Cardiothorac Surg. 2014;46(4):593-601. https://doi.org/10.1093/ejcts/ezt510.

96. Koch L, Deiwick A, Schlie S, et al. Skin tissue generation by laser cell printing. Biotechnol Bioeng. 2012;109(7):185563. https://doi.org/10.1002/bit.24455.

97. Lee V, Singh G, Trasatti JP, et al. Design and fabrication of human skin by three-dimensional bioprinting. Tissue Eng Part C Methods. 2014;20(6):473-84. https://doi.org/10.1089/ten.TEC.2013.0335.

98. Hsieh FY, Lin HH, Hsu SH. 3D bioprinting of neural stem cell-laden thermoresponsive biodegradable polyurethane hydrogel and potential in central nervous system repair. Biomaterials. 2015;71:48-57. https://doi.org/10.1016/j. biomaterials.2015.08.028.

99. Wang JZ, Xiong NY, Zhao LZ, et al. Review fantastic medical implications of 3D-printing in liver surgeries, liver regeneration, liver transplantation and drug hepatotoxicity testing: a review. Int J Surg. 2018;56:1-6. https://doi. org/10.1016/j.jisu.2018.06.004.

100. Grigoryan B, Paulsen SJ, Corbett DC, et al. Multivascular networks and functional intravascular topologies within biocompatible hydrogels. Science. 2019;364(6439):458-64. https://doi.org/10.1126/science.aav9750.

101. Isaacson A, Swioklo S, Connon CJ. 3D bioprinting of a corneal stroma equivalent. Exp Eye Res. 2018;173:188-93. https://doi.org/10.1016/j.exer.2018.05.010.

102. Pourmehran O, Gorji TB, Gorji-Bandpy M. Magnetic drug targeting through a realistic model of human tracheobronchial airways using computational fluid and particle dynamics. Biomech Model Mechanobiol. 2016;15(5):1355-74. https://doi.org/10.1007/s10237-016-0768-3.

103. Yousefi M, Pourmehran O, Gorji-Bandpy M, et al. CFD simulation of aerosol delivery to a human lung via surface acoustic wave nebulization. Biomech Model Mechanobiol. 2017;16(6):2035-50. https://doi.org/10.1007/s1023 7-017-0936-0.

104. Craven BA, Aycock KI, Herbertson LH, et al. A CFD-based Kriging surrogate modeling approach for predicting device-specific hemolysis power law coefficients in blood-contacting medical devices. Biomech Model Mechanobiol. 2019;18(4):1005-300. https://doi.org/10.1007/s10237-019-01126-4.

105. Yoon SH, Bleiziffer S, Latib A, Eschenbach L, Ancona M, Vincent F, et al. Predictors of left ventricular outflow tract obstruction after transcatheter mitral valve replacement. JACC Cardiovasc Interv. 2019;12(2):182-93. https://doi. org/10.1016/j.jcin.2018.12.001.

106. Nicol ED, Norgaard BL, Blanke P, Ahmadi A, Weir-McCall J, Horvat PM, et al. The future of cardiovascular computed tomography: advanced analytics and clinical insights. JACC Cardiovasc Imaging. 2019;12(6):1058-72. https://doi. org/10.1016/j.jcmg.2018.11.037.

\section{Publisher's Note}

Springer Nature remains neutral with regard to jurisdictional claims in published maps and institutional affiliations. 